\title{
Markers of epithelial-mesenchymal transition in an experimental breast cancer model induced by organophosphorous pesticides and estrogen (Review)
}

\author{
GLORIA M. CALAF ${ }^{1,2}$, TAMMY C. BLEAK ${ }^{1}$, JUAN P. MUÑOZ ${ }^{1}$ and FRANCISCO AGUAYO ${ }^{3,4}$ \\ ${ }^{1}$ Instituto de Alta Investigación, Universidad de Tarapacá, Arica 1000000, Chile; ${ }^{2}$ Center for Radiological Research, \\ Columbia University Medical Center, New York, NY 10032, USA; ${ }^{3}$ Programa de Virología, Instituto de Ciencias Biomédicas, \\ Facultad de Medicina; ${ }^{4}$ Advanced Center for Chronic Diseases (ACCDiS), Universidad de Chile, Santiago 8380000, Chile
}

Received December 19, 2019; Accepted July 1, 2020

DOI: 10.3892/ol.2020.11945

\begin{abstract}
Breast cancer is a major health problem and accounted for $11.6 \%$ of all new cancer cases and $6.6 \%$ of all cancer deaths among women worldwide in 2018. However, its etiology has remained elusive. According to epidemiological studies, environmental factors are influencing the increase in the incidence of breast cancer risk. Components such as chemicals, including pesticides, are agents that produce deleterious effects on wildlife and humans. Among them, the organophosphorus pesticides, such as malathion, have largely been considered in this etiology. The epithelial-mesenchymal transition serves a key role in tumor progression and it is proposed that malathion is closely associated with the origin of this transition, among other causes. Moreover, proteins participating in this process are primordial in the transformation of a normal cell to a malignant tumor cell. The aim of the current study was to evaluate markers that indicated oncogenic properties. The results indicated greater expression levels of proteins associated with the epithelial-to-mesenchymal transition, including E-cadherin, Vimentin, Axl, and Slug in the rat mammary glands treated with malathion alone and combined with estrogen. Atropine was demonstrated to counteract the malathion effect as a muscarinic antagonist. The understanding of the use of markers in experimental models is crucial to identify different stages in the cancer process. The alteration of these markers may serve as a predicting factor that can be used to indicate whether a person has altered ducts or lobules in breast tissue within biopsies of individuals exposed to OPs or other environmental substances.
\end{abstract}

Correspondence to: Dr Gloria M. Calaf, Instituto de Alta Investigación, Universidad de Tarapacá, 1520 Calle Antofagasta, Arica 1000000, Chile

E-mail: gmc24@cumc.columbia.edu

Key words: carcinogenesis, rat, mammary gland, malathion, atropine

\section{Contents}

1. Introduction

2. Data collection methods

3. Experimental induced rat mammary gland cancer model

4. Epithelial-to-mesenchymal transition (EMT)

5. Main findings

6. Conclusions and future perspectives

\section{Introduction}

Breast cancer is a major health problem, it accounted for $11.6 \%$ of all new cancer cases and $6.6 \%$ of all cancer deaths among women worldwide in 2018 and its etiology has thus far remained unidentified (1). According to epidemiological studies, environmental factors are influencing the increase in the incidence of breast cancer risk (2). Components as chemicals, including pesticides, are agents that produce deleterious effects on wildlife and humans (3-13).

Pesticides constitute a diverse class of xenobiotics used to protect crops and increase agricultural production. Among them, the organophosphorus pesticides (OPs) are the most commonly active insecticide used in the world $(3,4)$. There is evidence that chronic exposure to these compounds can have adverse effects on human health. Notably, pesticide exposure has been associated with an increased incidence of various diseases such as non-Hodgkin's lymphoma, multiple myeloma, soft tissue sarcoma, lung sarcoma, and several types of cancer, including pancreas, stomach, liver, bladder, and gallbladder cancer, as well as Alzheimer's and Parkinson's disease. Studies seeking to monitor people exposed to pesticides have shown several indicators of DNA damage, such as chromosomal aberrations, sister chromatid exchanges, micronuclei, and single-cell gel electrophoresis, among others (14-16). Previous studies have associated the increase of cancer risk with long-term exposure to several OPs in different countries, including in the USA $(5,6,8,9)$, Canada (7), and Italy (10) by both occupational and non-occupational exposures (11-13). For instance, malathion has been used to control a variety of pests in crops $(17,18)$. Furthermore, this pesticide has been associated with 
certain adverse effects, such as obesity and type 2 diabetes mellitus (19-21) and carcinogenicity (18).

The present review aimed to identify markers that exhibit properties of cell transformation based on a model that helps to define whether malathion or other substances affect the mammary gland and that may complement traditional markers for breast cancer in humans.

\section{Data collection methods}

For this review article, a thorough search on MEDLINE (through PubMed), Web of Science, and SCOPUS was performed from inception to May 2019 to identify studies addressing EMT as markers for the long-term effect of environmental pesticides.

\section{Experimental induced rat mammary gland cancer model}

Experimental mammary gland induced cancer models allow the ability to study the cellular and molecular mechanisms involved in breast carcinogenesis and gain an insight into the factors controlling cell proliferation of the normal mammary epithelium, both essential for an improved understanding of breast cancer initiation. An experimental rat mammary gland induced-cancer model provided an opportunity to study not only cancer initiation but also to address questions on which markers to use facing exposure to environmental substances over long time exposure. To the best of our knowledge, Calaf $e t$ al was the first group to examine the association between OPs and breast cancer using both in vivo (22-26) and in vitro systems (27-32) and by a pesticide, specifically, malathion. Epithelial rat mammary gland cells underwent a stepwise transformation into malignant ones through an increase of structures called terminal end buds, important targets associated with rat mammary carcinogenesis $(22,33)$, these studies indicated that malathion alone induced changes exclusively at the duct level, increasing in size and number of cells per $\mathrm{mm}^{2}$ with time. Such ducts defined as ductal in the proliferation stage, since one notable finding was that as time progressed those structures were transformed into mammary gland tumors that revealed a similarity to ductal carcinomas in comparison with controls, as reported by the World Health Organization (34).

The administration of an endogenous substance such as estrogen increased the average number of lobules per $\mathrm{mm}^{2}$ of rat mammary glands in comparison with control and malathion at 30,124, 240 and 400 days after 5 days of treatment (24). The combination of the pesticide malathion and estrogen synergistically increased the number of such lobules following such treatment. Furthermore, markers for cancer detection such as c-myc, c-fos, CYP, and mutant p53 were up-regulated following 124 and 240 days after 5 days of treatment by the effect of malathion and estrogen. On the other hand, a combination of malathion and estrogen sharply induced pathological lesions in lung alveolar parenchyma, bronchiolar epithelial, and lymphatic tissues in comparison with control animals or animals treated with either substance alone (25). Thus, these results indicated an increase in the risk of rodent lung tumor formation by environmental exposure and endogenous substances. Furthermore, the same combination induced pathological lesions in glomeruli and convoluted tubules of the kidney indicating malignant transformation by exposure to environmental and endogenous substances (26). Thus, rat kidney tissues were analyzed for histomorphological and immunocytochemical alterations by the effect of malathion and $17 \beta$-estradiol (estrogen). The animals were injected malathion, estrogen, and the combination of both substances for 5 days and sacrificed 30, 124, 240 and 400 days after treatments. The results indicated that Vimentin protein expression was increased in convoluted tubules of animals treated with a combination of malathion and estrogen after 240 days of 5-day treatment and malignant proliferation was observed in the hilium zone. In summary, the combination of malathion and estrogen-induced pathological lesions in glomeruli, convoluted tubules, atypical cell proliferation, and malignant proliferation in the hilium zone and immunocytochemical alterations in comparison with control animals or animals treated with either substance alone concluding that an increased risk of kidney malignant transformation could be due to the exposure to environmental and endogenous substances (26).

On the other hand, malathion alone significantly increased the number of ducts of mammary glands in the proliferation stage. Whereas, the results indicated that there was no rat mammary tumor formation following the injection of atropine alone or in combination with the pesticide. A marker for cancer detection such as mutant p53 was up-regulated following treatment of malathion and down-regulated by atropine after 10 and 20 days. Atropine is a well-known parasympatholytic alkaloid used as an antidote for organophosphorus/carbamates poisonings (35).

In vitro studies revealed that either pesticide parathion or malathion alone or combined with estrogen-induced malignant transformation, as shown by anchorage-independent growth capability and invasive characteristics in comparison with the control as well as genomic instability, that is the frequency of loss of heterozygosity ( $\mathrm{LOH}$ ) and microsatellite instability (MSI) in the immortalized human breast epithelial cell line, MCF-10F. It was found that induced genomic instability altering p53 and c-Ha-ras protein and gene expression when treated with parathion or malathion alone and in combination with estrogen (32). MSI was found in malathion and estrogen-treated cells with a marker used for the p53 tumor suppressor gene at loci 17p13.1. The same combination of substances presented MSI with a marker used for c-Ha-ras mapped in chromosome $11 \mathrm{p} 14.1$, as well as mutations in c-Ha-ras for codons 12 and 61 . LOH was observed in codon 12 in the presence of estrogen or malathion alone. Parathion alone and combined with estrogen-induced MSI in codon 61 (32).

Interestingly, malathion was classified as 'probably carcinogenic' to humans (Group 2A) by the International Agency for Research on Cancer in 2017 (18). Thereafter, studies have confirmed the increase in risk with OP in several hormonal-mediated cancers, including breast, thyroid, and ovary, suggesting potential cancer risk among women (36-39).

\section{Epithelial-to-mesenchymal transition (EMT)}

EMT is a biological process that allows interactions between the epithelial cells and basement membranes, even in normal conditions. EMT is a phenotypic change in the epithelial 
cells that, under specific conditions, allows cells to acquire a mesenchymal phenotype characterized by increased motility and one of these specific conditions is the loss of the adhesion molecule, E-cadherin, an adhesion protein that induces the EMT process (40).

Regarding cell-cell interaction, classical cadherins are transmembrane proteins that participate in $\mathrm{Ca}^{2+}$-dependent cell adhesion $(41,42)$. Among them, the E-cadherin is a cell surface protein, functionally linked to a polarized epithelial phenotype $(43,44)$ and its intracellular region contains binding sites that interact with catenins and other regulatory proteins $(45,46)$.

Chen et al (40) investigated the E-cadherin expression patterns in primary breast cancers and metastatic lymph nodes and observed that E-cadherin expression was aberrant in invasive ductal cancer and their corresponding metastatic lymph nodes. E-cadherin expression in the metastasized lymph node was closely associated with tumor size and the number of metastasized lymph nodes (40). Other reports have indicated that overexpression of Slug suppressed E-cadherin expression, with an eventual decrease in intercellular adhesion $(47,48)$ and initiation of the EMT in breast cancer due to the loss of E-cadherin expression (49,50).

Among other proteins involved in EMT, it should be mentioned Vimentin as a structural protein that supports and anchors the position of organelles in the cytosol. It also controls the transport of low-density lipoprotein (LDL)-derived cholesterol from a lysosome to the site of esterification (51-53). Then, the EMT process allows tumor cells to undergo phenotypic changes the including migratory and invasive capabilities (54). Thus, EMT can be initiated by overexpression of certain proteins, for instance, Vimentin that is present in progression from in situ to invasive breast cancer (55). EMT induces the expression of other proteins such as fibronectin, $\mathrm{N}$-cadherin $(55,56)$. This process comprises loss of cell cohesiveness and reorganization of the cytoskeleton (54). It was observed that there was a greater level of Vimentin protein expression in the mammary gland of pesticide-treated rats when compared with the control with metastatic properties similar to results observed in patients with breast cancer (57).

Another one is Axl, a cell surface receptor that has emerged as a key facilitator of immune escape and drug-resistance in cancer cells, leading to aggressive and metastatic cancer (58). Axl belongs to the TAM family of receptor tyrosine kinases. In particular, Axl is the central regulator of various signaling pathways implicated in cancer (59) that upon binding with its ligand, growth arrest-specific protein 6 (Gas6), undergoes dimerization and autophosphorylation which subsequently activates the downstream signaling pathways associated with carcinogenesis, such as the phosphatidylinositol 3-kinase/protein kinase B and the nuclear factor- $\kappa \mathrm{B}(\mathrm{NFkB})$ signaling pathways $(60,61)$. Besides, Axl is an underlying oncogenic factor that is involved in the EMT process, which allows epithelial cells to undergo cell migration and invasion, inducing tumor progression (62).

\section{Main findings}

Firstly, the effect of malathion and estrogen was analyzed in these studies and showed that a combination of both substances caused malignant phenotypic alterations in mammary gland tissues and the changes increased progressively with time after exposure that was greater than control. The present study showed important histological alterations in the rat mammary gland treated with malathion, estrogen, and combination of both in comparison to controls (63).

Graphs of Fig. 1A-D correspond to the quantification of the effect of malathion $(\mathrm{M})$, estrogen $(\mathrm{E})$, and combinations of both substances $(\mathrm{M}+\mathrm{E})$ in comparison to control on (A) E-cadherin, (B) Vimentin, (C) Axl, and (D) Slug protein expression in lobules of rat mammary gland (lobules $/ \mathrm{mm}^{2}$ ). The results indicated that malathion alone did not change the number of lobules in sections immune-stained when compared with control, estrogen, and combinations of both substances. However, malathion and a combination with estrogen increased the number of lobules in the stage of proliferation in comparison with the control. Results were expressed as the average \pm standard error (SE) of the mean. Comparison between groups was determined by ANOVA and Dunnett's test using STATA 12 software (StataCorp LP) and P $\leq 0.05$ was considered to indicate a statistically significant difference. The stimulatory effect of estrogen was analyzed, and Fig. 2 shows the cross-section of representative images of mammary gland structures immune-stained with E-cadherin, Vimentin, Axl, and Slug by the effect of malathion (M), estrogen (E), and combination of both substances $(\mathrm{M}+\mathrm{E})$ in comparison to control (C).

Secondly, complementary, Calaf (63) studied E-cadherin, Slug, Axl, and Vimentin to analyze the effect of malathion and atropine as its antagonist that confirmed the malignant phenotypic alterations in rat mammary gland tissues. The changes increased progressively with time after exposure in comparison with control reaching mammary gland tumor formation. Graphs of Fig. 3A-D correspond to the quantification of the intensity of E-cadherin, Vimentin, Axl, and Slug protein expressions of ducts in the proliferation stage $\left(\mathrm{dsp} / \mathrm{mm}^{2}\right)$ by the effect of malathion (M), atropine (A), and combination of both substances $(\mathrm{M}+\mathrm{A})$ in comparison to control of rat mammary glands. The main findings indicated that the malathion-treated group had significantly $(\mathrm{P}<0.05)$ higher E-cadherin (Fig. 3A), Vimentin (Fig. 3B), Axl (Fig. 3C) and Slug (Fig. 3D) protein expression than the control, atropine, and combination of both. Interestingly, the malathion effect was counteracted by the effect of atropine providing evidence that a pesticide affects the mammary gland carcinogenesis as shown in an experimental induced mammary gland cancer model. Fig. 4 displays the cross-section of representative images showing the effect malathion (M), atropine (A), and combination of both substances $(\mathrm{M}+\mathrm{A})$ in comparison to control (C) on E-cadherin, Vimentin, Axl, and Slug protein expressions of ducts in stage of proliferation $\left(\mathrm{dsp} / \mathrm{mm}^{2}\right)$ of rat mammary glands.

\section{Conclusions and future perspectives}

In summary, we used several markers associated with EMT, including E-cadherin, Slug, Axl, and Vimentin. It was observed the counteracted effect of an antagonist such as atropine, or the stimulatory effect of estrogen as an endogenous factor in ductal and lobular rat mammary gland carcinomas, respectively. The present review demonstrated that EMT such as Slug 
A

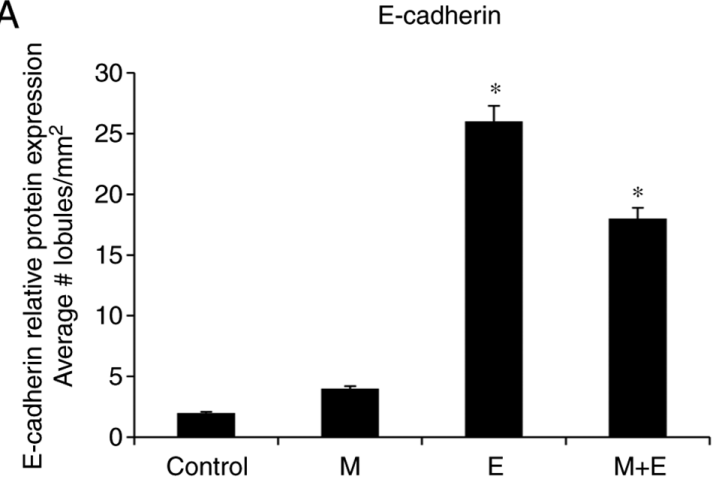

C

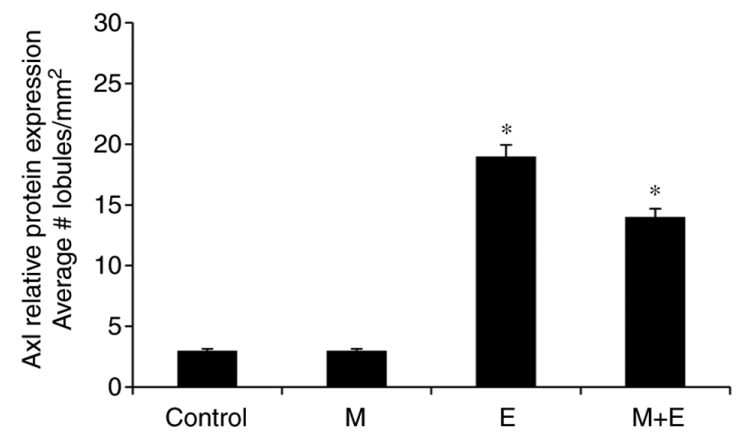

$\mathrm{B}$

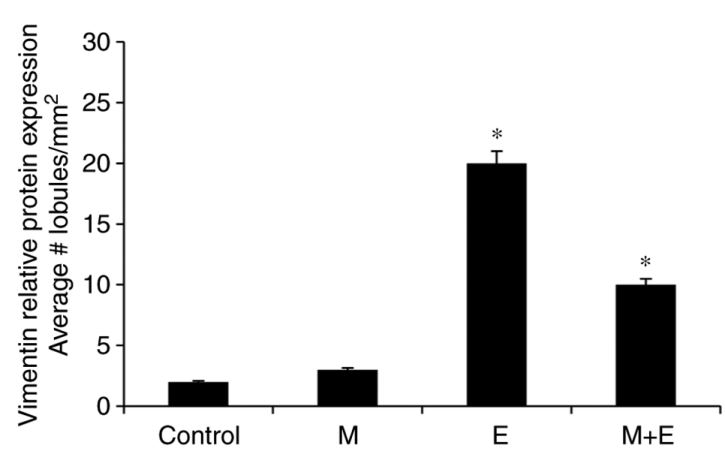

D

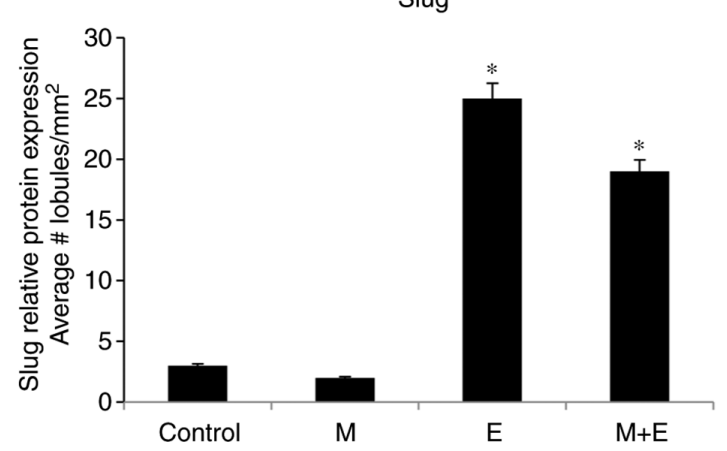

Figure 1. Graphs correspond to the quantification of the effect of M,E and combinations of both substances $(\mathrm{M}+\mathrm{E})$ in comparison to control on (A) E-cadherin, (B) Vimentin, (C) Axl and (D) Slug protein expression in lobules of rat mammary gland (lobules $/ \mathrm{mm}^{2}$ ). Results scored according to a scale from 0 to 30 points. The intensity of protein expression ratings: None ( 0 points), weak (10 points), slight (15 points), moderate ( 20 points), and intense ( 30 points). Structures were graded as 0 when the morphology of normal structure was present and there were no cells in the proliferative ducts. Results expressed as the average \pm standard error (SE) of the mean. Comparison between control and treated groups made by ANOVA and Dunnet's test (63). " $\mathrm{P}<0.05$. M, malathion; E, estrogen.

\section{Malathion and estrogen}
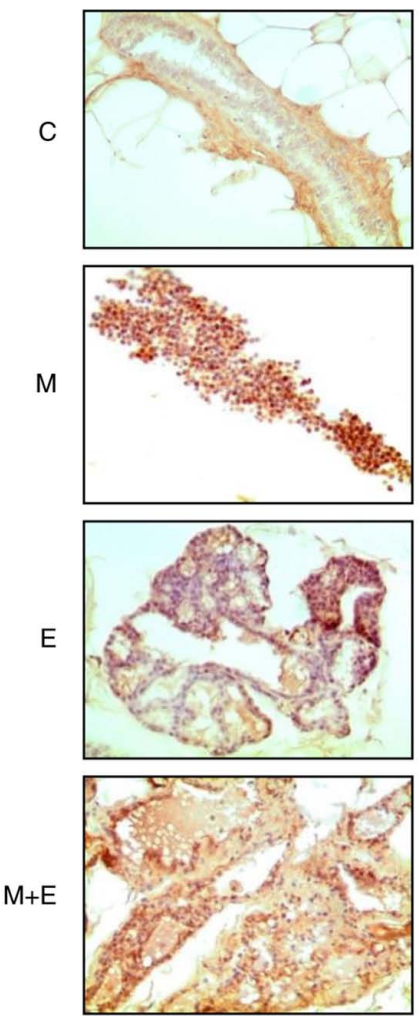

E-cadherin
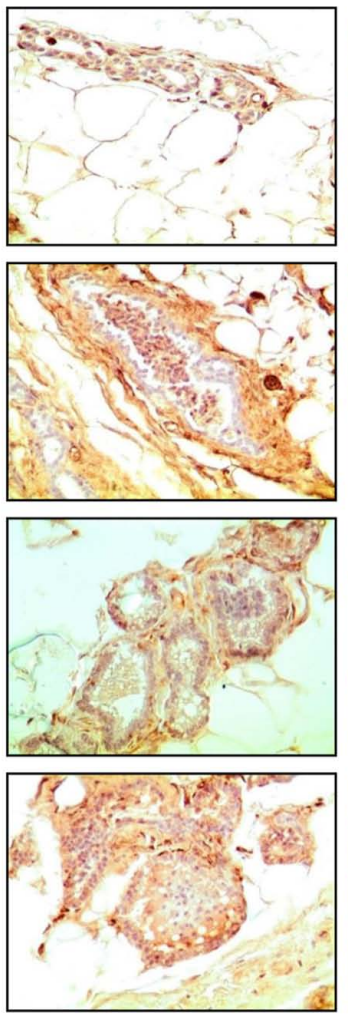

Vimentin
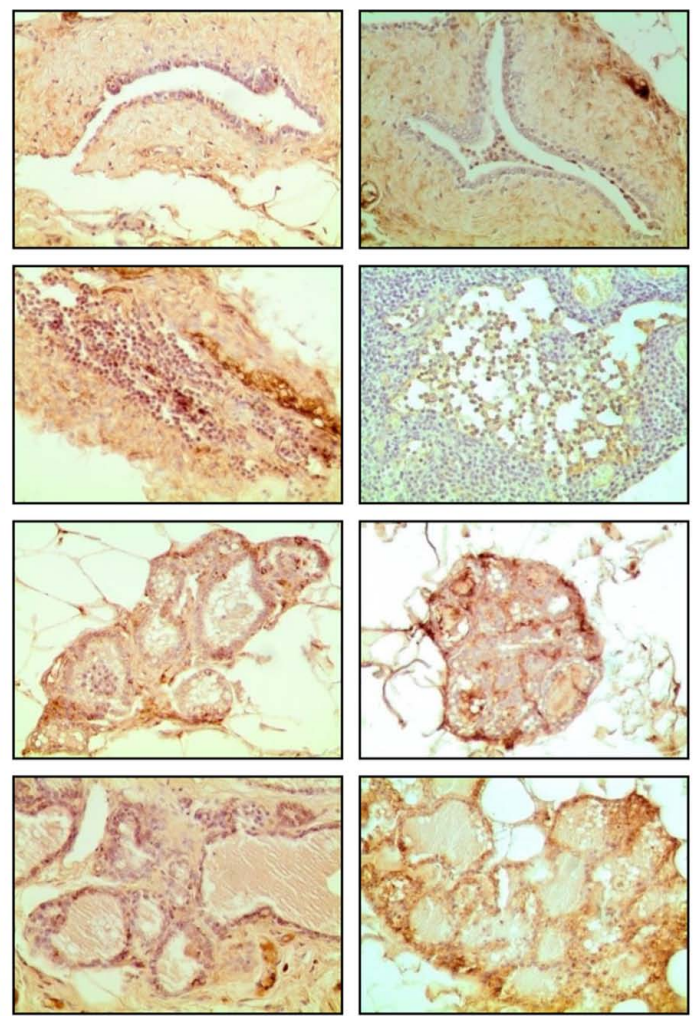

$\mathrm{Axl}$

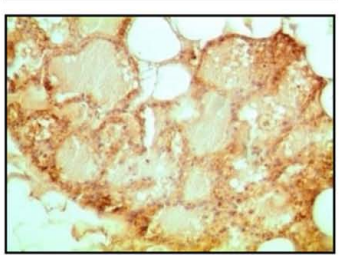

Slug

Figure 2. Cross-section of representative images showing the effect of control (C), malathion (M), estrogen (E) and combination of both substances (M+E) in comparison to control on E-cadherin, Vimentin, Axl, and Slug protein expression in lobules of rat mammary gland (63). C, control; M, malathion; E, estrogen. 
A

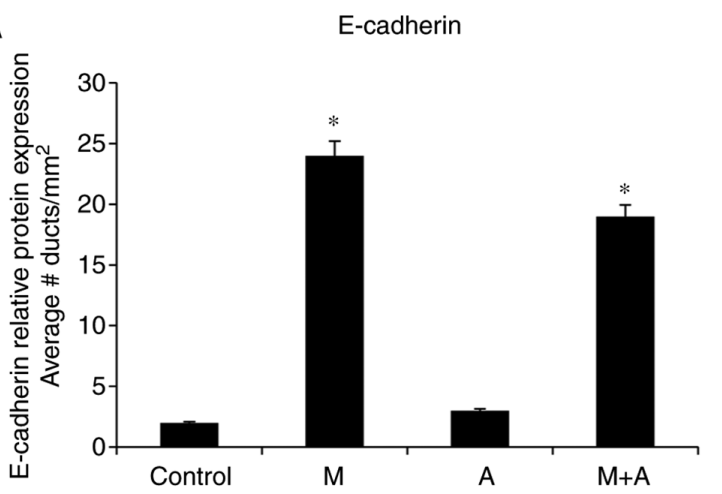

C

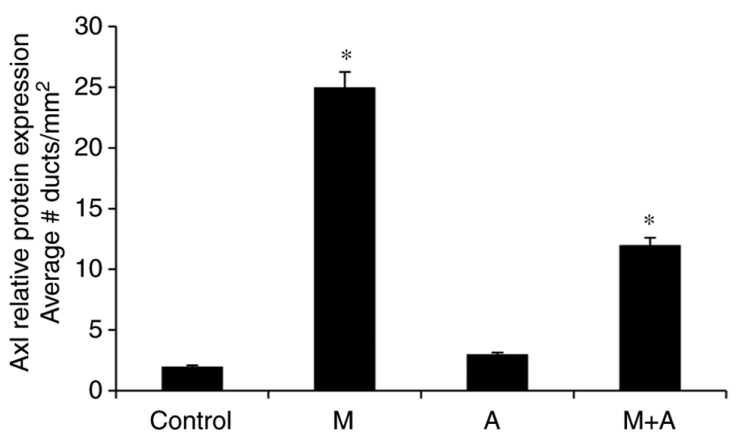

$\mathrm{B}$

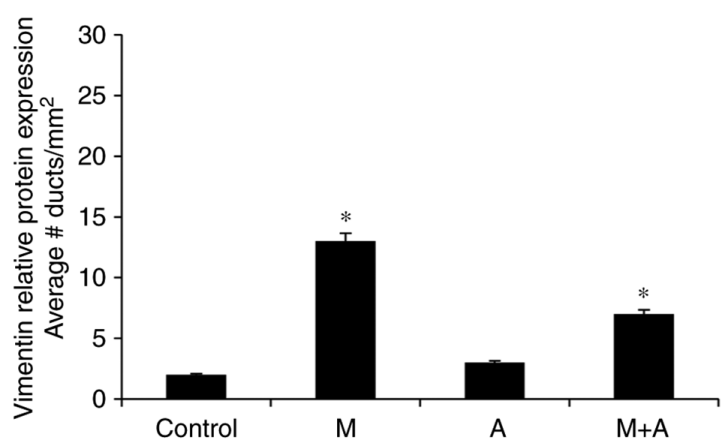

D

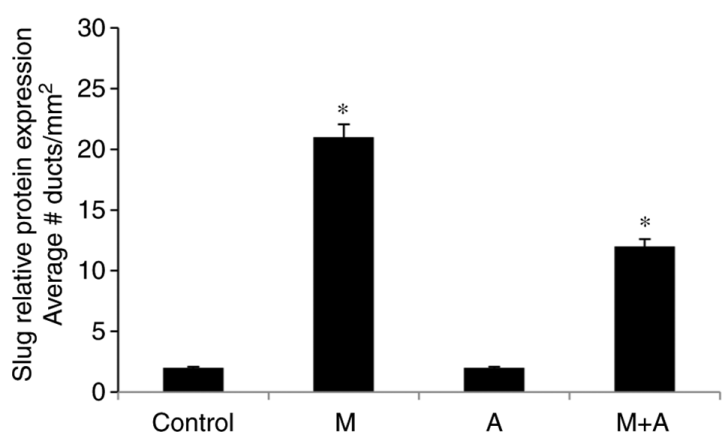

Figure 3. Graphs correspond to the quantification of the effect of $\mathrm{M}, \mathrm{A}$ and a combination of both substances $(\mathrm{M}+\mathrm{A})$ in comparison to control on (A) E-cadherin (sc-8426), (B) Vimentin (sc-6260), (C) Axl (sc-166269) and (D) Slug (sc-166476) protein expressions of ducts in stage of proliferation (dsp/mm²) of rat mammary glands. $(\mathrm{P}<0.05)$. (All antibodies from Santa Cruz Biotechnology, Inc.). Results scored according to a scale from 0 to 30 points. The intensity of protein expression ratings: None ( 0 points), weak (10 points), slight (15 points), moderate ( 20 points), and intense ( 30 points). Structures were graded as 0 when the morphology of normal structure was present and there were no cells in the proliferative ducts. Results expressed as the average \pm standard error (SE) of the mean. Comparison between control and treated groups made by ANOVA and Dunnet's test. "P<0.05. M, malathion; E, estrogen.
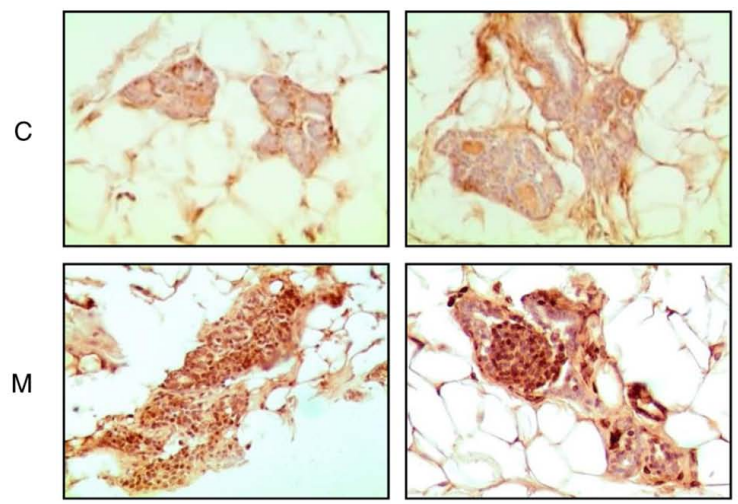

A
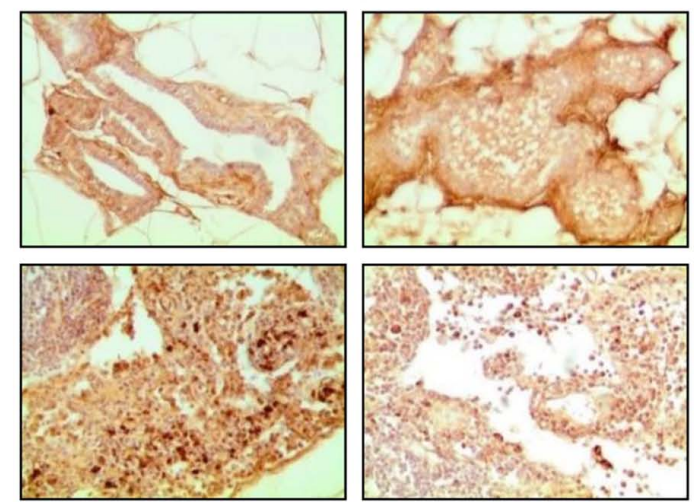

E-cadherin

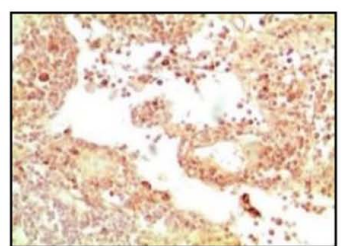

Vimentin
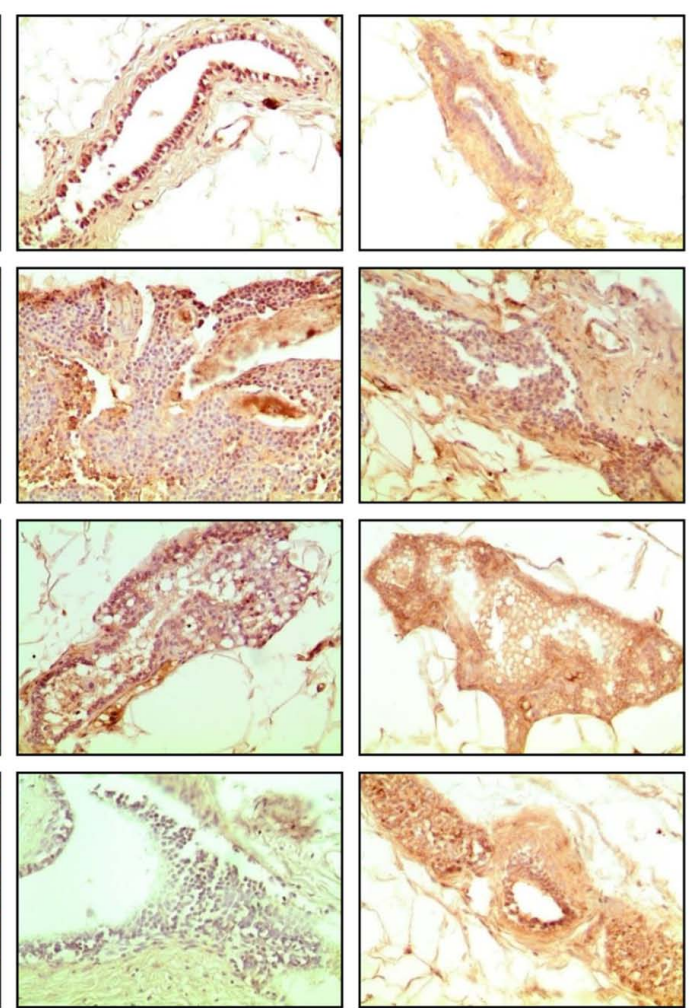

Axl

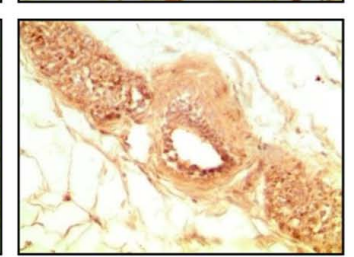

Slug

Figure 4. Cross-section of representative images showing the effect $\mathrm{M}, \mathrm{A}$ and combination of both substances $(\mathrm{M}+\mathrm{A})$ in comparison to $\mathrm{C}$ on E-cadherin, Vimentin, Axl, and Slug protein expressions in ducts in stage of proliferation $\left(\mathrm{dsp} / \mathrm{mm}^{2}\right)$ of rat mammary glands. C, control; M, malathion; E, estrogen. 
as well as E-cadherin, Vimentin, and Axl could be suitable biological markers for breast cancer progression, besides the traditional cancer markers. Alteration of these markers may serve as a predicting factor to indicate whether a person has altered ducts or lobules in breast tissues indicated in biopsies of persons exposed to OPs or other environmental substances.

\section{Acknowledgements}

The authors would like to thank Mrs. Georgina Vargas Marchant, Mrs. Guiliana Rojas and Mr. Leodán A. Crispin, (Instituto de Alta Investigación, Universidad de Tarapacá), for providing technical support.

\section{Funding}

The current study was supported by a grant from Universidad de Tarapacá, Convenio de Desempeño (grant no. UTA1117) to GMV, FONDECYT (grant no. 1200656) to GMC. Fondecyt (grant no. 1161219) to FA, Conicyt Fondap (grant no. 15130011) to FA, and FONDECYT (Postdoctoral grant no. 3190744) to JPM.

\section{Availability of data and materials}

The datasets used and/or analyzed during the current study are available from the corresponding author on reasonable request.

\section{Authors' contributions}

GMC wrote the manuscript, and JPM, FA and TCB edited and reviewed the manuscript and agreed to be accountable for all aspects of the revision in ensuring that the accuracy or integrity of any part of the work was appropriately conducted. All authors read and approved the final manuscript.

\section{Ethics approval and consent to participate}

Not applicable.

\section{Patient consent for publication}

Not applicable.

\section{Competing interests}

The authors declare that they have no competing interests.

\section{References}

1. Bray F, Ferlay J, Soerjomataram I, Siegel RL, Torre LA and Jemal A: Global cancer statistics 2018: GLOBOCAN estimates of incidence and mortality worldwide for 36 cancers in 185 countries. CA Cancer J Clin 68: 394-424, 2018.

2. Knower KC, To SQ, Leung YK, Ho SM and Clyne CD: Endocrine disruption of the epigenome: A breast cancer link. Endocr Relat Cancer 21: T33-T55, 2014.

3. Grube A, Donaldson D, Kiely T and Wu L: Pesticide industry sales and usage: 2006 and 2007 market estimates. US Environmental Protection Agency. Washington DC, 2011. https://www.epa. gov/pesticides/pesticides-industry-sales-and-usage-2006-and-20 07-market-estimates Accessed Aug 2018.
4. EPA: Mosquito control: Malathion. US Environmental Protection Agency, 2014. https://www.epa.gov/mosquitocontrol/malathion. Accessed Aug 2018

5. IARC: Agents classified by the IARC monographs. Vols 1-122. International Agency for Research on Cancer, World Health Organization, Lyon, France, 2018. https://monographs.iarc. fr/agents-classified-by-the-iarc/. Accessed Aug 2018.

6. De Roos AJ, Zahm SH, Cantor KP, Weisenburger DD, Holmes FF, Burmeister LF and Blair A: Integrative assessment of multiple pesticides as risk factors for non-Hodgkin's lymphoma among men. Occup Environ Med 60: E11, 2003.

7. McDuffie HH, Pahwa P, McLaughlin JR, Spinelli JJ, Fincham S, Dosman JA, Robson D, Skinnider LF and Choi NW: Non-Hodgkin's lymphoma and specific pesticide exposures in men: Cross-canada study of pesticides and health. Cancer Epidemiol Biomarkers Prev 10: 1155-1163, 2001.

8. Mills PK and Yang R: Prostate cancer risk in California farm workers. J Occup Environ Med 45: 249-258, 2003.

9. Pesatori AC, Sontag JM, Lubin JH, Consonni D and Blair A: Cohort mortality and nested case-control study of lung cancer among structural pest control workers in Florida (United States). Cancer Causes Control 5: 310-318, 1994.

10. Miligi L, Costantini AS, Bolejack V, Veraldi A, Benvenuti A, Nanni O, Ramazzotti V, Tumino R, Stagnaro E, Rodella S, et al: Non-Hodgkin's lymphoma, leukemia, and exposures in agriculture: Results from the Italian multicenter case-control study. Am J Ind Med 44: 627-636, 2003.

11. Klaasen C: Nonmetallic environmental toxicants: Air pollutants, solvents and vapors, and pesticides. In: The Pharmacological Basis of Therapeutics. Goodman RT, Gilman A, Nies AS and Taylor P (eds.). Pergamon Press Inc, New York, pp1615-1635, 1990.

12. EPA: Registration review; Draft malathion human health risk assessment. US Environmental Protection Agency: Washington DC, 2016.https://www3.epa.gov/pesticides/PrePublicationCopy Malathion_DraftRA-NoA_16P-0230_signed.pdf. Accessed Aug 2018.

13. EPA: Revised Chlorpyrifos Human Health Risk Assessment. US Environmental Protection Agency. Washington DC, 2014. http://www.regulations.gov/ Accessed Aug 2018.

14. Bernieri T, Moraes MF, Ardenghi PG and Basso da Silva L: Assessment of DNA damage and cholinesterase activity in soybean farmers in southern Brazil: High versus low pesticide exposure. J Environ Sci Health B 55: 355-360, 2020.

15. Kapka-Skrzypczak L, Cyranka M, Skrzypczak M and Kruszewski M: Biomonitoring and biomarkers of organophosphate pesticides exposure-state of the art. Ann Agric Environ Med 18: 294-303, 2011

16. Shah HK, Sharma T and Banerjee BD: Organochlorine pesticides induce inflammation, ROS production, and DNA damage in human epithelial ovary cells: An in vitro study. Chemosphere 246: 125691, 2020.

17. Guyton KZ, Loomis D, Grosse Y, El Ghissassi F, Benbrahim-Tallaa L, Guha N, Scoccianti C, Mattock H and Straif K; International Agency for Research on Cancer Monograph Working Group, IARC, Lyon, France: Carcinogenicity of tetrachlorvinphos, parathion, malathion, diazinon, and glyphosate. Lancet Oncol 16: 490-491, 2015.

18. IARC: Some organophosphate insecticides and herbicides. IARC Working Group on the Evaluation of Carcinogenic Risks to Humans. Volume 112. International Agency for Research on Cancer.Lyon,France, 2017.https://monographs.iarc.fr/iarc-monographs-on-the-evaluation-of-carcinogenic-risks-to-humans-4/. Accessed July 2017.

19. Elobeid MA, Padilla MA, Brock DW, Ruden DM and Allison DB: Endocrine disruptors and obesity: An examination of selected persistent organic pollutants in the NHANES 1999-2002 data. Int J Environ Res Public Health 7: 2988-3005, 2010.

20. Everett CJ, Frithsen IL, Diaz VA, Koopman RJ, Simpson WM Jr and Mainous AG III: Association of a polychlorinated dibenzo-p-dioxin, a polychlorinated biphenyl, and DDT with diabetes in the 1999-2002 national health and nutrition examination Survey. Environ Res 103: 413-418, 2007.

21. Beard J and Australian Rural Health Research Collaboration: DDT and human health. Sci Total Environ 355: 78-89, 2006.

22. Calaf GM, Parra E and Garrido F: Cell proliferation and tumor formation induced by eserine, an acetylcholinesterase inhibitor, in rat mammary gland. Oncol Rep 17: 25-33, 2007.

23. Calaf GM and Garrido F: Catechol estrogens as biomarkers for mammary gland cancer. Int J Oncol 39: 177-183, 2011. 
24. Calaf GM and Echiburu-Chau C: Synergistic effect of malathion and estrogen on mammary gland carcinogenesis. Oncol Rep 28: 640-646, 2012.

25. Echiburu-Chau $\mathrm{C}$ and Calaf GM: Rat lung cancer induced by malathion and estrogen. Int J Oncol 33: 603-611, 2008.

26. Alfaro-Lira S, Pizarro-Ortiz M and Calaf GM: Malignant transformation of rat kidney induced by environmental substances and estrogen. Int J Environ Res Public Health 9: 1630-1648, 2012.

27. Calaf GM and Roy D: Human drug metabolism genes in parathion-and estrogen-treated breast cells. Int J Mol Med 20 : 875-881, 2007.

28. Calaf GM and Roy D: Gene and protein expressions induced by 17beta-estradiol and parathion in cultured breast epithelial cells Mol Med 13: 255-265, 2007.

29. Calaf GM and Roy D: Gene expression signature of parathion-transformed human breast epithelial cells. Int J Mol Med 19: 741-750, 2007.

30. Calaf GM and Roy D: Cancer genes induced by malathion and parathion in the presence of estrogen in breast cells. Int J Mol Med 21: 261-268, 2008

31. Calaf GM and Roy D: Cell adhesion proteins altered by 17 beta estradiol and parathion in breast epithelial cells. Oncol Rep 19: $165-169,2008$.

32. Calaf GM, Echiburu-Chau C and Roy D: Organophosphorous pesticides and estrogen induce transformation of breast cells affecting p53 and c-Ha-ras genes. Int J Oncol 35: 1061-1068, 2009.

33. Cabello G, Valenzuela M, Vilaxa A, Duran V, Rudolph I, Hrepic N and Calaf G: A rat mammary tumor model induced by the organophosphorous pesticides parathion and malathion, possibly through acetylcholinesterase inhibition. Environ Health Perspect 109: 471-479, 2001.

34. Hoon Tan P, Ellis I, Allison K, Brogi E, Fox SB, Lakhani S, Lazar AJ, Morris EA, Sahin A, Salgado R, et al: The 2019 WHO classification of tumours of the breast. Histopathology: Feb 13, 2020 (Epub ahead of print).

35. Taylor P: Anticholinesterase agents. In: The Pharmacological Basis of Therapeutics. Goodman RT, Gilman A, Nies AS and Taylor P (eds). Pergamon Press Inc., New York, pp131-147, 1990.

36. Omran $\mathrm{OM}$ and Omer $\mathrm{OH}$ : The effects of alpha-lipoic acid on breast of female albino rats exposed to malathion: Histopathological and immunohistochemical study. Pathol Res Pract 211: 462-469, 2015.

37. Nilsson E, Klukovich R, Sadler-Riggleman I, Beck D, Xie Y, Yan W and Skinner MK: Environmental toxicant induced epigenetic transgenerational inheritance of ovarian pathology and granulosa cell epigenome and transcriptome alterations: Ancestral origins of polycystic ovarian syndrome and primary ovarian insufiency. Epigenetics 13: 875-895, 2018

38. Skinner MK, Manikkam M, Tracey R, Guerrero-Bosagna C, Haque $\mathrm{M}$ and Nilsson EE: Ancestral dichlorodiphenyltrichloroethane (DDT) exposure promotes epigenetic transgenerational inheritance of obesity. BMC Med 11: 228, 2013.

39. Kao CC, Que DE, Bongo SJ, Tayo LL, Lin YH, Lin CW, Lin SL, Gou YY, Hsu WL, Shy CG, et al: Residue levels of organochlorine pesticides in breast milk and its associations with cord blood thyroid hormones and the Offspring's neurodevelopment. Int J Environ Res Public Health 16: 1438, 2019.

40. Chen L, Jian W, Lu L, Zheng L, Yu Z and Zhou D: Elevated expression of E-cadherin in primary breast cancer and its corresponding metastatic lymph node. Int J Clin Exp Med 8: $11752-11758,2015$.

41. Gumbiner BM: Regulation of cadherin-mediated adhesion in morphogenesis. Nat Rev Mol Cell Biol 6: 622-634, 2005.

42. Tepass U: Genetic analysis of cadherin function in animal morphogenesis. Curr Opin Cell Biol 11: 540-548, 1999.

43. Wheelock MJ and Jensen PJ: Regulation of keratinocyte intercellular junction organization and epidermal morphogenesis by E-cadherin. J Cell Biol 117: 415-425, 1992.

44. Jeanes A, Gottardi CJ and Yap AS: Cadherins and cancer: How does cadherin dysfunction promote tumor progression? Oncogene 27: 6920-6929, 2008 .
45. Shapiro L and Weis WI: Structure and biochemistry of cadherins and catenins. Cold Spring Harb Perspect Biol 1: a003053, 2009.

46. Perez-Moreno $M$ and Fuchs E: Catenins: Keeping cells from getting their signals crossed. Dev Cell 11: 601-612, 2006.

47. Alves CC, Carneiro F, Hoefler $\mathrm{H}$ and Becker KF: Role of the epithelial-mesenchymal transition regulator Slug in primary human cancers. Front Biosci (Landmark Ed) 14: 3035-3050, 2009.

48. Kim J, Bae S, An S, Park JK, Kim EM, Hwang SG, Kim WJ and Um HD: Cooperative actions of p21WAF1 and p53 induce Slug protein degradation and suppress cell invasion. EMBO Rep 15: 1062-1068, 2014

49. Chen J, Imanaka N, Chen J and Griffin JD: Hypoxia potentiates Notch signaling in breast cancer leading to decreased E-cadherin expression and increased cell migration and invasion. $\mathrm{Br}$ J Cancer 102: 351-360, 2010.

50. Hajra KM, Chen DY and Fearon ER: The SLUG zinc-finger protein represses E-cadherin in breast cancer. Cancer Res 62: 1613-1618, 2002.

51. Wong SHM, Fang CM, Chuah LH, Leong CO and Ngai SC E-cadherin: Its dysregulation in carcinogenesis and clinical implications. Crit Rev Oncol Hematol 121: 11-22, 2018.

52. Liu T, Zhang X, Shang M, Zhang Y, Xia B, Niu M, Liu Y and Pang D: Dysregulated expression of Slug, vimentin, and E-cadherin correlates with poor clinical outcome in patients with basal-like breast cancer. J Surg Oncol 107: 188-194, 2013.

53. Myong NH: Loss of E-cadherin and acquisition of vimentin in epithelial-mesenchymal transition are noble indicators of uterine cervix cancer progression. Korean J Pathol 46: 341-348, 2012.

54. Guarino M, Rubino B and Ballabio G: The role of epithelial-mesenchymal transition in cancer pathology. Pathology 39: 305-318, 2007.

55. Foroni C, Broggini M, Generali D and Damia G: Epithelial-mesenchymal transition and breast cancer: Role, molecular mechanisms and clinical impact. Cancer Treat Rev 38: 689-697, 2012

56. Singh A and Settleman J: EMT, cancer stem cells and drug resistance: An emerging axis of evil in the war on cancer. Oncogene 29: 4741-4751, 2010.

57. Calaf GM, Balajee AS, Montalvo-Villagra MT, Leon M, Daniela NM, Alvarez RG, Roy D, Narayan G and Abarca-Quinones J: Vimentin and Notch as biomarkers for breast cancer progression. Oncol Lett 7: 721-727, 2014.

58. Davidsen KT, Haaland GS, Lie MK, Lorens JB and Engelsen AST: The role of Axl receptor tyrosine kinase in tumor cell plasticity and therapy resistance. In: Biomarkers of the Tumor Microenvironment: Basic Studies and Practical Applications. Akslen LA and Watnick RS (eds). Springer, Switzerland, pp351-376, 2017.

59. Meyer AS, Miller MA, Gertler FB and Lauffenburger DA: The receptor AXL diversifies EGFR signaling and limits the response to EGFR-targeted inhibitors in triple-negative breast cancer cells. Sci Signal 6: ra66, 2013.

60. Yanagita M, Arai H, Nakano T, Ohashi K, Mizuno K, Fukatsu A, Doi T and Kita T: Gas6 induces mesangial cell proliferation via latent transcription factor STAT3. J Biol Chem 276: 42364-42369, 2001.

61. Linger RM, Keating AK, Earp HS and Graham DK: TAM receptor tyrosine kinases: Biologic functions, signaling, and potential therapeutic targeting in human cancer. Adv Cancer Res 100: 35-83, 2008.

62. Tai KY, Shieh YS, Lee CS, Shiah SG and Wu CW: Axl promotes cell invasion by inducing MMP-9 activity through activation of NF-kappaB and Brg-1. Oncogene 27: 4044-4055, 2008.

63. Calaf GM: Carcinogenicity of malathion and estrogen in an experimental rat mammary gland model. Siberian J Oncol 17: $5-13,2018$.

This work is licensed under a Creative Commons Attribution-NonCommercial-NoDerivatives 4.0 International (CC BY-NC-ND 4.0) License. 